\title{
FAKTOR - FAKTOR YANG MEMPENGARUHI KUALITAS PELAYANAN TERHADAP KEPUASAN KONSUMEN MENGGUNAKAN METODE ANALISIS FAKTOR
}

\author{
Murta $^{1, a)}$ Tabah Heri Setiawan ${ }^{2, b)}$ \\ ${ }^{1}$ Program Studi Matematika FMIPA Universitas Pamulang \\ ${ }^{2}$ Program Studi Matematika FMIPA Universitas Pamulang \\ Email: ${ }^{\text {a) }}$ murta.nadia@gmail.com ${ }^{\text {b) }}$ tabah.ibnubara@ gmail.com
}

\begin{abstract}
The purpose of this study is to find out the factors that affect the quality of service to customer satisfaction through a reduction process at the Sabar Subur Cikupa Tangerang Store. In this study used the method of factor analysis with the Principal Component Analysis technique using SPSS 22 software. Based on the results of this factor analysis, three factors that influence the quality of service on customer satisfaction are obtained, the first factor (F6) with a correlation value of 0.661 with variables X2.2 (0.897), X5.5 (0.912), the second factor (F4) with a correlation value of 0.164 with variables X1.2 (0.861), X1.3 (0.753), X2.4 (0.864), X4.4 (0.730), and the third factor (F1) with a correlation value of 0.152 with variables X2.3 (0.940), X3.1 (0.836), X4.5 (0.929), X5.3 $(0.931)$, the fourth factor $(F 2)$ with a correlation value of -0.288 with variables X1.5 (0.745), X2.5 (0.788), X3.2 (0.621), X4.1 (0.488) X5.1 (0.771), X5.2 (0.843), the fifth factor (F5) with a correlation value of -0.315 with variables X1.1 (0.734), X3.3 (0.761), $X 3.5$ (0.809), X4.2 (0.829), the sixth factor (F3) with a correlation value of -0.783 with variables X1.4 (0.605), X2.1 (0.921), X3.4 (0.884), X4.3 (0.572), X5.4 (0.906). From the results of the study it can be concluded that the factors F1, F2, F3, F4, F5 and F6 affect the quality of service to customer satisfaction at the Sabar Subur Cikupa Tangerang Store.
\end{abstract}

Keywords: Factor Analysis, Service Quality, Consumer Satisfaction, Principal Component Analysis

\begin{abstract}
ABSTRAK
Tujuan penelitian ini adalah untuk mengetahui faktor-faktor yang mempengaruhi kualitas pelayanan terhadap kepuasan konsumen melalui proses reduksi pada Toserba Sabar Subur Cikupa Tangerang. Dalam penelitian ini digunakan metode Analisis Faktor dengan teknik Principal Component Analysis dengan menggunakan software SPSS 22. Berdasarkan hasil dari penelitian analisis faktor ini, diperoleh tiga faktor yang mempengaruhi kualitas pelayanan terhadap kepuasan konsumen yaitu faktor yang pertama (F6) dengan nilai korelasi 0,661 dengan variabel X2.2 (0,897), X5.5 (0,912), faktor yang ke dua $(\mathrm{F} 4)$ dengan nilai korelasi 0,164 dengan variabel X1.2 (0,861), X1.3 $(0,753), \mathrm{X} 2.4(0,864), \mathrm{X} 4.4(0,730)$, dan faktor yang ke tiga $(\mathrm{F} 1)$ dengan nilai korelasi 0,152 dengan variabel X2.3 (0,940), X3.1 (0,836), X4.5 (0,929), X5.3 (0,931), faktor yang ke empat $(\mathrm{F} 2)$ dengan nilai korelasi $-0,288$ dengan variabel X1.5 $(0,745), \mathrm{X} 2.5$ $(0,788)$, X3.2 (0,621), X4.1 (0,488) X5.1 (0,771), X5.2 (0,843), faktor yang ke lima (F5) dengan nilai korelasi -0,315 dengan variabel X1.1 (0,734), X3.3 $(0,761)$, X3.5 $(0,809)$,
\end{abstract}


X4.2 (0,829), faktor yang ke enam (F3) dengan nilai korelasi -0,783 dengan variabel X1.4 $(0,605)$, X2.1 (0,921), X3.4 (0,884), X4.3 (0,572) X5.4 (0,906). Dari hasil penelitian dapat disimpulkan bahwa faktor F1, F2, F3, F4, F5 dan F6 mempengaruhi kualitas pelayanan terhadap kepuasan konsumen pada Toserba Sabar Subur Cikupa Tangerang.

Kata kunci: Analisis Faktor, Kualitas Pelayanan, Kepuasan Konsumen, Principal Component Analysis

\section{PENDAHULUAN}

Sektor industri merupakan salah satu sektor penunjang berhasilnya pembangunan ekonomi, dengan demikian tidaklah mengherankan apabila semakin banyak perusahaan berdiri akan tetapi tidak semua akan berhasil dengan baik seperti yang diinginkan tanpa ditunjang oleh pengelolaan manajemen yang profesional. Ketatnya persaingan membuat perusahaan-perusahaan tersebut berusaha keras untuk mempertahankan konsumen dan memperoleh konsumen yang baru untuk membeli produknya. Perusahaan-perusahaan tersebut memberdayakan segala fungsi dan bidang yang ada, termasuk bidang pemasaran serta sumber daya manusia yang dimilikinya. Seiring dengan semakin ketatnya persaingan menimbulkan fenomena baru yang terjadi pada konsumen, yaitu adanya perilaku perpindahan pembelian produk kepada perusahaan lain yang dilakukan oleh konsumen.

Perubahan yang langsung disegala bidang di Indonesia, menimbulkan perubahan sosial ekonomi yang selanjutnya mengakibatkan perubahan lingkungan industri. Pertumbuhan ekonomi Indonesia menghadapi krisis global yang terjadi pada beberapa waktu lalu, sangat berpengaruh besar pada daya beli masyarakat dimana akibat krisis tersebut daya beli masyarakat menjadi menurun bahkan lemah. Lemahnya daya beli masyarakat ini disebabkan melambungnya harga barang dan masuknya pesaing dari Negara asing yang mempunyai pengelolaan manajemen yang lebih baik.

Keadaan ini yang membuat perusahaan harus memiliki kemampuan membaca keadaan pasar dan mengantasipasinya dengan cara melakukan strategi pemasaran yang sesuai dengan perkembangan, sehingga usaha untuk memenuhi target pemasaran yang telah direncanakan tidak mengalami penurunan. Untuk meningkatkan volume penjualan, perusahaan harus berupaya melakukan strategi pemasaran agar produk atau jasa yang dihasilkan memenuhi kepuasan konsumen.

Hal ini menimbulkan persaingan yang ketat dalam usaha untuk mendapatkan dan mepertahankan konsumen sebanyak-banyaknya. Dengan berbagai cara setiap perusahaan melalukan terobosan-terobosan yang inovatif dalam memasarkan produknya, untuk menarik minat konsumen. Hal-hal yang paling sering dilakukan oleh perusahaan adalah dengan cara meningkatkan daya beli konsumen dan memberikan trend baru pada konsumen sesuai dengan perkembangan zaman dan kebutuhan konsumen itu sendiri.

Setiap konsumen yang datang pasti akan berharap mendapatkan pelayanan yang prima, walaupun tujuan utamanya adalah membeli sebuah produk. Tidak bisa dipungkiri bahwa dengan pelayanan prima yang memberi kepuasaan, akan membuat konsumen itu 
loyal dan akan menjadi tujuan utama konsumen untuk datang kembali membeli produk yang sama bahkan produk yang berbeda. Pelayanan sebuah perusahaan terhadap konsumen bukan hanya pada saat pembelian produk yang dicari konsumen tersebut, bahkan pelayanan setelah transaksi pembelian produk atau yang biasa disebut dengan pelayanan purna jual dapat meningkatkan kepuasan dan kepercayaan konsumen terhadap perusahaan.

Semakin tinggi kualitas pelayanan yang diberikan oleh perusahaan maka semakin tinggi pula tingkat kepuasan konsumen sehingga menjadi pelanggan yang loyal. Walaupun pada dasarnya pelayanan tersebut dalam bentuk kasat mata, tetapi dengan memberi pelayanan yang ekstra dengan empati yang tinggi dari karyawan menjadikan tolak ukur kinerja perusahaan yang berkualitas.

Buruknya kualitas pelayanan yang diberikan oleh perusahaan dapat mengakibatkan pada kunjungan konsumen untuk berbelanja, kualitas produk harus diimbangi dengan pelayanan yang maksimal. Cara terbaik dalam bertahan dipersaingan retail adalah pelayanan, ada beberapa dimensi kualitas pelayanan yang dapat mempengaruhi perilaku pelanggan, yaitu meliputi persepsi yang berhubungan dengan sarana fisik (Tangibles), kehandalan (Reliability), daya tanggap (Responsiveness), jaminan (Assurance), dan empati (Emphaty) yang dapat diukur dengan instrumen SERVQUAL. Hasil pengukuran dengan instrumen tersebut memberikan informasi tentang seberapa jauh layanan yang diberikan oleh perusahaan dapat memenuhi harapan pelanggan.

Toserba Sabar Subur dan Subur sebagai perusahaan retail tertua di kota Tangerang, selalu berusaha meningkatkan kualitas perusahaan. Sejauh ini berfokus kepada peningkatan laba dengan memberikan promo-promo yang menarik kepada konsumen baik itu promo yang dilakukan oleh perusahaan sendiri maupun promo yang dilakukan melalui kerjasama dengan supplier. Kesiapan dan kemampuan serta kualitas SDM yang ada perlu ditingkatkan agar pencapaian kepuasan konsumen serta pelayanan terhadap konsumen semakin berkualitas dan memuaskan. Indikator dari pencapaian tersebut bukan hanya dilihat dari laba yang didapatkan, tetapi juga bisa dilihat dari kualitas SDM yang dimiliki dan kepuasan konsumen sehingga menjadi konsumen yang loyal akibat dari pelayanan karyawan terhadap konsumen yang baik.

Semakin meningkatnya jumlah konsumen yang ingin berbelanja maka semakin tinggi pula produktivitas kerja yang dituntut oleh perusahaan untuk membuat para konsumen tetap selalu berbelanja dan tidak berpindah ketempat lain. Dengan selalu memberikan pelayanan terbaik kepada konsumen agar konsumen bisa tetap setia berbelanja di Toserba Sabar Subur Cikupa Tangerang, hal ini membuktikan dengan kualitas kinerja karyawan yang optimal.

Sebagai contoh di daerah Cikupa Tangerang, pada saat pertama kali operasional tahun 2003, saat itu pesaing dalam radius 1-2 KM hanya terdapat kurang dari 20 kompetitor itu pun yang berskala kecil (minimarket). Tetapi hal ini berbanding terbalik yang terjadi pada 2018, kompetitor sudah melebihi dari jumlah di tahun 2003, yaitu 
terdapat 190 kompetitor. Baik itu minimarket maupun perusahaan retail nasional seperti Alfamart, Indomaret, Giant dan Ramayana yang kita tahu memiliki manajemen yang lebih baik dari Toserba Sabar Subur, ini tidak termasuk dengan usaha kecil lokal yang ada seperti agent, toko susu, toko make up, apotik dan lain sebagainya. Terkadang kompetitor lokal yang berskala kecil lebih memberikan harga rendah dengan yang dijual di Sabar Subur.

Dari total jumlah kompetitor ditentukan berdasarkan atas kondisi kompetitor yang bersifat permanen atau yang mempunyai bangunan tetap, tetapi ada juga kompetitor lain yang menjual produknya pada waktu-waktu tertentu saja, misalnya seperti pagi hari, menjelang malam atau akhir pekan. Biasanya kompetitor ini bersifat nomaden dan menjual produk tidak banyak dan sangat tidak variatif.

Mengingat pentingnya masalah tersebut, maka penulis tertarik untuk melakukan penelitian dengan fenomena yang terjadi pada saat observasi dilapangan, tentang "Faktor-faktor Yang Mempengaruhi Kualitas Pelayanan Terhadap Kepuasan Konsumen Menggunakan Metode Analisis Faktor".

\section{METODOLOGI PENELITIAN}

Penelitian yang dilakukan merupakan studi kasus yang terperinci mengenai suatu obyek dalam kurun waktu tertentu. Dalam kasus ini penelitian dilakuakan secara insidental. Metode insidental adalah teknik penelitian berdasarkan kebetulan, yaitu siapa saja yang secara kebetulan bertemu dengan peneliti dapat digunakan sebagai sampel, bila dipandang orang yang kebetulan ditemui cocok sebagai sumber data (Sugiyono, 2011:67). Penelitian ini dilaksanakan di Toserba Sabar Subur Cikupa, yang beralamat di Jalan raya Serang Km 15, Kel. Sukamulya - Cikupa, Kab. Tangerang 15710, yang dimulai tanggal 1 sampai 31 Agustus 2018 dari Konsumen Toserba Sabar Subur Cikupa Tangerang.

Untuk populasi penelitian peneliti mengambil populasi dari pengunjung atau konsumen yang datang berbelanja pada Toserba Sabar Subur Cikupa Tangerang dengan jumlah yang terhingga sehingga diperlukan populasi target yakni keseluran pengunjung selama bulan agustus 2018, sedangkan untuk sampel data diambil secara insidental sebanyak 100 responden.

Metode pengumpulan data yang digunakan dalam penelitian ini adalah dengan mengambil sampel dari suatu target obyek dengan menggunakan kuesioner sebagai alat pengumpul data pokok.

Terdapat 5 variabel Variabel yang digunakan dalam penelitian ini adalah sebagai berikut:

a. Kehandalan/Reliability adalah kemampuan kayawan Toserba Sabar Subur Cikupa Tangerang dalam memberikan pelayanan yang di janjikan dengan segera, akurat dan memuaskan. 
b. Daya tanggap/Responsiveness adalah keinginan para karyawan Toserba Sabar Subur Cikupa Tangerang untuk membantu konsumen dan memberikan pelayanan dengan baik.

c. Jaminan/Assurance yaitu mencakup pengetahuan, kemampuan, kesopanan dan sikap dapat dipercaya yang dimiliki para karyawan Toserba Sabar Subur Cikupa Tangerang dari bahaya, dan resiko dan keragu-raguan.

d. Empati/Emphaty meliputi kemudahan dalam hubungan antara karyawan Toserba Sabar Subur Cikupa Tangerang dengan konsumen. Komunikasi yang baik. Perhatian yang baik. Dan memenuhi kebutuhan konsumen.

e. Tampilan Fisik/Tangible yaitu meliputi fasilitas fisik, perlengkapan, karyawan, dan sarana komunikasi yang tersedia pada Toserba Sabar Subur Cikupa Tangerang.

Tahapan dalam analisa data dalam penelitian ini dari awal sampai akhir adalah sebagai berikut :

a. Menguji validitas instrumen dengan menggunakan rumus Korelasi Product Moment.

$$
r_{x y}=\frac{n\left(\sum X Y\right)-\left(\sum X\right)\left(\sum Y\right)}{\sqrt{\left[n\left(\sum X^{2}\right)-\left(\sum X\right)^{2}\right]\left[n\left(\sum Y^{2}\right)-\left(\sum Y\right)^{2}\right]}}
$$

b. Menguji Reliabilitas instrumen dengan menggunakan rumus Alpha Crobach.

$$
r_{11}=\left[\frac{K}{K-1}\right]\left[1-\frac{\sum \sigma_{b}^{2}}{\sigma_{t}^{2}}\right]
$$

c. Menganalisis Faktor dengan tahapan sebagai berikut:

1) Uji Independensi Variabel yakni pengujian apakah antar variabel yang satu dengan yang lain mempunyai keterkaitan atau tidak. Dimana terdapat kemungkinan lebih dari dua variabel berkorelasi. Variabel yang digunakan untuk analisis selanjutnya hanya variabel yang mempunyai korelasi dengan variabel lain dan variabel yang hampir tidak mempunyai korelasi dengan variabel lain, maka variabel tersebut akan dikeluarkan dari analisis. Pengujian dilakukan melalui pengamatan terhadap ukuran kecukupan sampling (MSA), nilai KMO dan hasil uji Barlett.

2) Bentuk Matriks Korelasi, dimana proses analisis didasarkan pada suatu matriks korelasi agar variabel pendalaman yang berguna bisa diperoleh dari penelitian matriks ini

3) Menentukan Metode Analisis Faktor malalui dua cara atau metode yang bisa dipergunakan dalam analisis faktor, khususnya untuk menghitung timbangan atau koefisien skor faktor, yaitu principal components analysis (PCA) dan common factor analysis.

4) Penentuan Banyaknya Faktor, prinsip melakukan analisis faktor ialah mencari variabel baru yang disebut faktor yang saling tidak berkorelasi, bebas satu sama lainnya, lebih sedikit jumlahnya daripada variabel asli, akan tetapi bisa 
menyerap sebagian informasi yangterkandung dalam variabel asli atau yang bisa member sumbangan terhadap varian seluruh variabel.

5) Mengekstraksi Faktor, Ekstraksi faktor menggunakan Principal Component Analysis (PCA). Dalam metode ini diharapkan dapat diperoleh hasil yang memaksimumkan persentase varian yang mampu di jelaskan dengan model.

6) Melakukan Rotasi Faktor-faktor, Suatu hasil output yang penting dari analisis faktor ialah apa yang disebut matriks faktor pola (factor pattern matrix). Matriks faktor berisi koefisien yang dipergunakan untuk mengekspresikan variabel yang dibakukan (standardized) dinyatakan dalam faktor. Suatu koefisien dengan nilai absolute/mutlak yang besar menunjukan bahwa faktor bisa dipergunakan untuk menginterpretasikan faktor.

7) Menginterpretasikan Faktor, interpretasi dipermudah dengan mengenali/ mengidentifikasi variabel yang muatannya (loadingnya) besar pada faktor yang sama. Faktor tersebut kemudian bisa di interpretasikan, dinyatakan dalam variabel yang mempunyai high loading. Manfaat lainnya didalam membantu untuk membuat interpretasi ialah menge-plot variabel, dengan menggunakan faktor loading sebagai

\section{HASIL DAN PEMBAHASAN}

\subsection{Hasil Penelitian}

\subsubsection{Hasil Uji Validitas}

Tabel 1. Uji Validitas

\begin{tabular}{|c|c|c|c|c|}
\hline Dimensi & Atribut & Nilai rhitung & Nilai $\mathrm{rt}_{\text {abel }}$ & Keterangan \\
\hline \multirow{5}{*}{$\begin{array}{l}\text { Reliability } \\
\left(\mathrm{X}_{1}\right)\end{array}$} & $\mathrm{X}_{1.1}$ & 0,760 & 0,195 & Valid \\
\hline & $\mathrm{X}_{1.2}$ & 0,670 & 0,195 & Valid \\
\hline & $\mathrm{X}_{1.3}$ & 0,713 & 0,195 & Valid \\
\hline & $\mathrm{X}_{1.4}$ & 0,725 & 0,195 & Valid \\
\hline & $\mathrm{X}_{1.5}$ & 0,691 & 0,195 & Valid \\
\hline \multirow{5}{*}{$\begin{array}{l}\text { Responsivenes } \\
{ }_{s}\left(\mathrm{X}_{2}\right)\end{array}$} & $\mathrm{X}_{2.1}$ & 0,708 & 0,195 & Valid \\
\hline & $\mathrm{X}_{2.2}$ & 0,428 & 0,195 & Valid \\
\hline & $\mathrm{X}_{2.3}$ & 0,340 & 0,195 & Valid \\
\hline & $\mathrm{X}_{2.4}$ & 0,628 & 0,195 & Valid \\
\hline & $\mathrm{X}_{2.5}$ & 0,382 & 0,195 & Valid \\
\hline \multirow{4}{*}{$\begin{array}{l}\text { Assurance } \\
\left(\mathrm{X}_{3}\right)\end{array}$} & $X_{3.1}$ & 0,449 & 0,195 & Valid \\
\hline & $\mathrm{X}_{3.2}$ & 0,534 & 0,195 & Valid \\
\hline & $X_{3.3}$ & 0,719 & 0,195 & Valid \\
\hline & $\mathrm{X}_{3.4}$ & 0,676 & 0,195 & Valid \\
\hline
\end{tabular}




\begin{tabular}{|l|l|l|l|l|}
\hline Dimensi & Atribut & Nilai $\mathrm{r}_{\text {hitung }}$ & Nilai $\mathrm{rt}_{\text {abel }}$ & Keterangan \\
\hline \multirow{5}{*}{$\begin{array}{l}\text { Emphaty } \\
\left(\mathrm{X}_{4}\right)\end{array}$} & $\mathrm{X}_{3.5}$ & 0,631 & 0,195 & Valid \\
\cline { 2 - 5 } & $\mathrm{X}_{4.1}$ & 0,604 & 0,195 & Valid \\
\cline { 2 - 5 } & $\mathrm{X}_{4.2}$ & 0,624 & 0,195 & Valid \\
\cline { 2 - 5 } & $\mathrm{X}_{4.3}$ & 0,762 & 0,195 & Valid \\
\cline { 2 - 5 } & $\mathrm{X}_{4.4}$ & 0,595 & 0,195 & Valid \\
\cline { 2 - 5 } & $\mathrm{X}_{4.5}$ & 0,304 & 0,195 & Valid \\
\hline \multirow{4}{*}{$\left(\mathrm{X}_{5}\right)$} & $\mathrm{X}_{5.1}$ & 0,529 & 0,195 & Valid \\
\cline { 2 - 5 } & $\mathrm{X}_{5.2}$ & 0,730 & 0,195 & Valid \\
\cline { 2 - 5 } & $\mathrm{X}_{5.3}$ & 0,301 & 0,195 & Valid \\
\cline { 2 - 5 } & $\mathrm{X}_{5.4}$ & 0,658 & 0,195 & Valid \\
\cline { 2 - 5 } & $\mathrm{X}_{5.5}$ & 0,373 & 0,195 & Valid \\
\hline
\end{tabular}

Pada Tabel 3.1 nilai r-hitung semua item pernyataan lebih besar dari nilai r-tabel, maka semua item pernyataan dalam kuesioner dinyatakan valid.

3.1.2. Hasil Uji Reliabilitas.

Tabel 2. Uji Reliabilitas

Reliability Statistics

\begin{tabular}{|c|c|c|}
\hline $\begin{array}{c}\text { Cronbach' } \\
\text { s Alpha }\end{array}$ & $\begin{array}{c}\text { Cronbach's Alpha } \\
\text { Based on } \\
\text { Standardized } \\
\text { Items }\end{array}$ & $\begin{array}{c}\text { N of } \\
\text { Items }\end{array}$ \\
\hline, 919 &, 919 & 25 \\
\hline
\end{tabular}

Berdasarkan matriks tabel 3.2 dimana nilai Cronbach's Alpha 0,919 dan nilai tersebut lebih besar dari 0,6, maka instrumen yang digunakan reliabel.

\subsubsection{Uji Asumsi Analisis Faktor}

Uji asumsi analisis faktor dilakukan satu persatu terlebih dahulu sebelum uji analisis faktor dilakukan. Korelasi antarvariabel independen dalam analisis faktor harus >0,5 dengan signifikansi $<0,05$. Ukuran yang digunakan sebagai penguji asumsi melalui pengamatan terhadap nilai Keiser-Meyer-Olikn (KMO), hasil uji barlett dan ukuran kecukupan sampling (MSA) dengan menggunakan software SPSS 22.

Tabel 3. Hasil Uji KMO dan Barlett's Test

KMO and Bartlett's Test

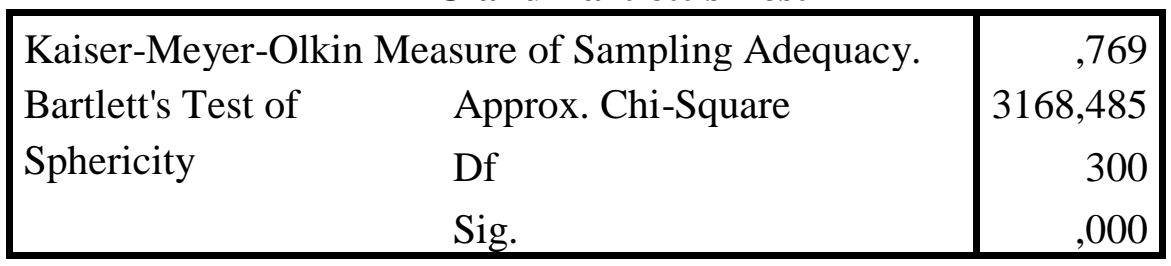


Dari hasil perhitungan (output SPSS) diperoleh nilai signifikansi yang dihasilkan Barlett's Test of Spericity sebesar 0,000. Untuk nilai KMO sebesar 0,769 yang artinya lebih besar dari 0,5. Sedangkan hasil MSA dapat dilihat dari Anti Image Correlation. Dimana terdapat deretan diagonal angka bertanda 'a' yang menunjukan besaran MSA masing-masing atribut (ada di lampiran 10). Angka MSA tiap atribut tidak boleh kurang dari 0,5. Dengan menggunakan software SPSS 22.

Hasil MSA untuk 25 atribut yang di analisis dapat dilihat pada tabel 4.4 dan dari ketiga uji yang dilakukan nilai MSA > 0,5 maka langkah analisis faktor dapat dilanjutkan.

Tabel 1. Nilai Measure of Sampling Adequancy (MSA)

\begin{tabular}{|c|c|c|}
\hline Dimensi & Atribut & Nilai MSA \\
\hline \multirow{5}{*}{$\begin{array}{l}\text { Reliability } \\
\qquad\left(\mathrm{X}_{1}\right)\end{array}$} & $\mathrm{X}_{1.1}$ & 0,773 \\
\hline & $\mathrm{X}_{1.2}$ & 0,716 \\
\hline & $\mathrm{X}_{1.3}$ & 0,793 \\
\hline & $\mathrm{X}_{1.4}$ & 0,741 \\
\hline & $\mathrm{X}_{1.5}$ & 0,825 \\
\hline \multirow{5}{*}{$\begin{array}{l}\text { Responsiveness } \\
\qquad\left(\mathrm{X}_{2}\right)\end{array}$} & $\mathrm{X}_{2.1}$ & 0,753 \\
\hline & $\mathrm{X}_{2.2}$ & 0,700 \\
\hline & $\mathrm{X}_{2.3}$ & 0,685 \\
\hline & $\mathrm{X}_{2.4}$ & 0,686 \\
\hline & $\mathrm{X}_{2.5}$ & 0,773 \\
\hline \multirow{5}{*}{$\begin{array}{c}\text { Assurance } \\
\left(\mathrm{X}_{3}\right)\end{array}$} & $X_{3.1}$ & 0,800 \\
\hline & $\mathrm{X}_{3.2}$ & 0,775 \\
\hline & $X_{3.3}$ & 0,768 \\
\hline & $\mathrm{X}_{3.4}$ & 0,844 \\
\hline & $\mathrm{X}_{3.5}$ & 0,795 \\
\hline \multirow{5}{*}{$\begin{array}{l}\text { Emphaty } \\
\qquad\left(\mathrm{X}_{4}\right)\end{array}$} & $\mathrm{X}_{4.1}$ & 0,859 \\
\hline & $\mathrm{X}_{4.2}$ & 0,789 \\
\hline & $\mathrm{X}_{4.3}$ & 0,774 \\
\hline & $\mathrm{X}_{4.4}$ & 0,733 \\
\hline & $\mathrm{X}_{4.5}$ & 0,660 \\
\hline \multirow{4}{*}{$\begin{array}{c}\text { Tangible } \\
\left(\mathrm{X}_{5}\right)\end{array}$} & $X_{5.1}$ & 0,839 \\
\hline & $X_{5.2}$ & 0,823 \\
\hline & $X_{5.3}$ & 0,820 \\
\hline & $\mathrm{X}_{5.4}$ & 0,811 \\
\hline
\end{tabular}




\begin{tabular}{|c|c|c|}
\hline Dimensi & Atribut & Nilai MSA \\
\hline & $\mathrm{X}_{5.5}$ & 0,645 \\
\hline
\end{tabular}

\subsubsection{Ekstraksi Faktor}

Tabel 5. Uji Proses Principal Component Analysis (PCA)

\section{Communalities}

\begin{tabular}{|c|c|c|}
\hline & Initial & Extraction \\
\hline X1.1 & 1,000 &, 856 \\
X1.2 & 1,000 &, 862 \\
X1.3 & 1,000 &, 813 \\
X1.4 & 1,000 &, 730 \\
X1.5 & 1,000 &, 780 \\
X2.1 & 1,000 &, 945 \\
X2.2 & 1,000 &, 894 \\
X2.3 & 1,000 &, 915 \\
X2.4 & 1,000 &, 831 \\
X2.5 & 1,000 &, 698 \\
X3.1 & 1,000 &, 758 \\
X3.2 & 1,000 &, 630 \\
X3.3 & 1,000 &, 817 \\
X3.4 & 1,000 &, 873 \\
X3.5 & 1,000 &, 858 \\
X4.1 & 1,000 &, 630 \\
X4.2 & 1,000 &, 869 \\
X4.3 & 1,000 &, 746 \\
X4.4 & 1,000 &, 670 \\
X4.5 & 1,000 &, 896 \\
X5.1 & 1,000 &, 788 \\
X5.2 & 1,000 &, 905 \\
X5.3 & 1,000 &, 881 \\
X5.4 & 1,000 &, 881 \\
X5.5 & 1,000 &, 894 \\
\hline
\end{tabular}

Extraction Method: Principal

Component Analysis.

Berdasarkan tabel diatas, hasil yang didapat dari proses ekstraksi faktor yang memiliki eigenvalue lebih besar dari 1 sebanyak 3 faktor. Maka dapat dilihat dari hasil scree plot berikut ini: 
Gambar 1 Scree Plot pada proses ekstraksi

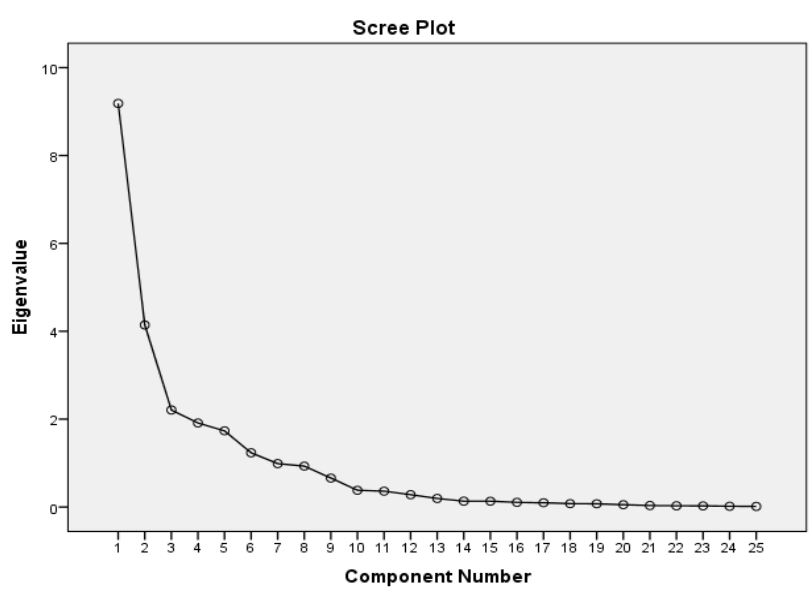

Dari hasil scree plot diatas terlihat bahwa dari satu ke dua faktor (garis sumbu Commponent Number $=1$ ke 2 ) arah garis menurun dengan cukup tajam. Kemudian dari angka 2 ke 3, angka 3 ke 4, angka 4 ke 5 garis masih menurun. Demikian pula dari angka 5 ke 6, namun kini dengan slope yang lebih kecil. Juga perhatikan faktor ke 7 sudah dibawah angka 1 dari sumbu Y (eigenvalue). Dari penjelasan diatas dapat ditarik kesimpulan untuk meringkas 25 variabel yaitu F1, F2, F3, F4, F5 dan F6.

\subsubsection{Faktor Yang Terbentuk}

Selanjutnya dilakukan perhitungan nilai total variance explained agar dapat melihat nilai-nilai eigenvalue dan nilai-nilai variance explained untuk masing-masing atribut, seperti pada tabel dibawah ini.

Tabel 6. Total Variance Explained

\begin{tabular}{|c|c|c|c|c|c|c|c|c|c|}
\hline \multicolumn{10}{|c|}{ Total Variance Explained } \\
\hline \multirow[b]{2}{*}{ Component } & \multicolumn{3}{|c|}{ Initial Eigenvalues. } & \multicolumn{3}{|c|}{ Extraction Sums of Squared Loadings } & \multicolumn{3}{|c|}{ Rotation Sums of Squared Loadings } \\
\hline & Total & $\%$ of Variance & Cumulative $\%$ & Total & $\%$ of Variance & Cumulative $\%$ & Total & $\%$ of Variance & Cumulative $\%$ \\
\hline 1 & 9,185 & 36,739 & 36,739 & 9,185 & 36,739 & 36,739 & 3,960 & 15,838 & 15,838 \\
\hline 2 & 4,143 & 16,572 & 53,311 & 4,143 & 16,572 & 53,311 & 3,837 & 15,349 & 31,188 \\
\hline 3 & 2,208 & 8,833 & 62,143 & 2,208 & 8,833 & 62,143 & 3,814 & 15,257 & 46,445 \\
\hline 4 & 1,911 & 7,646 & 69,789 & 1,911 & 7,646 & 69,789 & 3,563 & 14,250 & 60,695 \\
\hline 5 & 1,734 & 6,935 & 76,725 & 1,734 & 6,935 & 76,725 & 3,293 & 13,171 & 73,866 \\
\hline 6 & 1,234 & 4,936 & 81,661 & 1,234 & 4,936 & 81,661 & 1,949 & 7,795 & 81,661 \\
\hline 7 & 988 & 3,952 & 85,613 & & & & & & \\
\hline 8 & 931 & 3,723 & 89,336 & & & & & & \\
\hline 9 & 659 & 2,635 & 91,972 & & & & & & \\
\hline 10 & 381 & 1,523 & 93,495 & & & & & & \\
\hline 11 & 362 & 1,446 & 94,941 & & & & & & \\
\hline 12 & 280 & 1,122 & 96,063 & & & & & & \\
\hline 13 &, 195 &, 780 & 96,844 & & & & & & \\
\hline 14 & 133 & 532 & 97,375 & & & & & & \\
\hline 15 &, 133 & 531 & 97,906 & & & & & & \\
\hline 16 &, 106 & 424 & 98,329 & & & & & & \\
\hline 17 & 096 & 385 & 98,715 & & & & & & \\
\hline 18 & 076 & 305 & 99,020 & & & & & & \\
\hline 19 & 074 & 297 & 99,317 & & & & & & \\
\hline 20 &, 052 & 209 & 99,526 & & & & & & \\
\hline 21 &, 034 &, 137 & 99,663 & & & & & & \\
\hline 22 & 027 & 108 & 99,772 & & & & & & \\
\hline 23 & 026 & 104 & 99,876 & & & & & & \\
\hline 24 &, 017 &, 070 & 99,945 & & & & & & \\
\hline 25 &, 014 &, 055 & 100,000 & & & & & & \\
\hline
\end{tabular}

Extraction Method: Principal Component Analysis 
Berdasarkan tabel diatas, dapat dilihat pada kolom component yang menunjukan bahwa ada 25 komponen yang mewakili variabel independen. Perhatikan kolom initial Eigenvalues yang dengan SPSS kita tentukan nilainya 1. Varians bisa diterangkan oleh faktor 1 adalah 9,185/25 x 100\%=36,739, faktor 2 sebesar 4,143/25 x 100\%=16,572, untuk faktor 3 sebesar 2,208/25 x 100\% =8,833, faktor 4 sebesar 1,911/25 x 100\%= 7,646 , faktor 5 sebesar 1,734/25 x 100\% = 6,935 dan faktor 6 sebesar 1,234/25 x 100\% $=4,936$ total ke enam faktor akan mampu menjelaskan variabel sebesar 36,739 + 16,572 $+8,833+7,646+6,935+4,936=81,661 \%$. Dengan demikian, karena nilai eigenvalues yang ditetapkan 1 , maka nilai total yan akan diambil adalah yang $>1$ yaitu component 1 , $2,3,4,5$ dan 6.

\subsubsection{Faktor Loading}

Setelah kita mengetahui bahwa faktor maksimal yang bisa terbentuk adalah 6 , selanjutnya kita melakukan penentuan masing-masing variabel independen akan masuk kedalam faktor 1 , faktor 2, faktor 3, faktor 4, faktor 5 dan faktor 6 . Cara menentukannya adalah dengan melihat tabel Component Matrix sebagai berikut:

Tabel 2. Component Matrix

Component Matrix ${ }^{\mathrm{a}}$

\begin{tabular}{|l|c|c|c|c|c|c|}
\hline & \multicolumn{7}{|c|}{ Component } \\
\cline { 2 - 7 } & 1 & 2 & 3 & 4 & 5 & 6 \\
\hline X1.1 &, 724 &, 311 &, 059 &,- 337 &,- 280 &, 201 \\
X1.2 &, 699 &,- 167 &, 248 &, 203 &,- 394 &,- 295 \\
X1.3 &, 744 &,- 160 &, 374 &,- 080 &,- 212 &,- 204 \\
X1.4 &, 753 &, 057 &,- 149 &, 297 &, 071 &,- 211 \\
X1.5 &, 729 &,- 012 &, 011 &,- 022 &, 484 &, 115 \\
X2.1 &, 665 &, 311 &,- 619 &, 115 &,- 039 &,- 094 \\
X2.2 &, 444 &,- 151 &, 088 &, 663 &,- 099 &, 466 \\
X2.3 &, 175 &, 909 &, 181 &, 031 &, 154 &,- 004 \\
X2.4 &, 646 &,- 137 &, 247 &, 208 &,- 433 &,- 321 \\
X2.5 &, 455 &,- 460 &, 175 &,- 032 &, 489 &,- 092 \\
X3.1 &, 327 &, 724 &, 335 &,- 037 &, 025 &, 108 \\
X3.2 &, 560 &,- 095 &, 468 &,- 091 &, 271 &, 078 \\
X3.3 &, 690 &, 259 &, 072 &,- 377 &,- 254 &, 250 \\
X3.4 &, 630 &, 303 &,- 606 &, 113 &,- 019 &,- 056 \\
X3.5 &, 694 &,- 262 &,- 155 &,- 391 &,- 159 &, 325 \\
X4.1 &, 629 &,- 166 &,- 076 &,- 418 &, 128 &,- 100 \\
X4.2 &, 682 &,- 241 &,- 176 &,- 433 &,- 193 &, 299 \\
X4.3 &, 793 &, 030 &,- 109 &, 264 &, 050 &,- 178 \\
X4.4 &, 622 &,- 143 &, 402 &,- 005 &,- 253 &,- 192 \\
X4.5 &, 139 &, 903 &, 188 &, 028 &, 150 &,- 047 \\
X5.1 &, 621 &,- 482 &, 057 &,- 012 &, 382 &,- 146 \\
X5.2 &, 779 &,- 098 &, 032 &, 002 &, 536 &, 039 \\
X5.3 &, 136 &, 889 &, 249 &, 023 &, 093 &,- 006 \\
X5.4 &, 624 &, 237 &,- 636 &, 135 &,- 041 &,- 110 \\
X5.5 &, 394 &,- 204 &, 150 &, 628 &,- 068 &, 525 \\
\hline
\end{tabular}

Extraction Method: Principal Component Analysis.

a. 6 components extracted. 
Agar lebih jelas variabel mana masuk ke faktor mana, bisa dilihat tabel 3.8 Rotated Component Matrix sebagai berikut:

Tabel 3. Rotated Component Matrix

Rotated Component Matrix ${ }^{\mathrm{a}}$

\begin{tabular}{|l|c|c|c|c|c|c|}
\hline & \multicolumn{7}{|c|}{ Component } \\
\cline { 2 - 7 } & 1 & 2 & 3 & 4 & 5 & 6 \\
\hline X1.1 &, 381 &, 082 &, 243 &, 324 &, 734 &, 042 \\
X1.2 &,- 029 &, 145 &, 212 &, 861 &, 153 &, 172 \\
X1.3 &, 057 &, 351 &, 047 &, 753 &, 338 &, 045 \\
X1.4 &, 116 &, 376 &, 605 &, 414 &, 037 &, 189 \\
X1.5 &, 181 &, 745 &, 303 &, 057 &, 259 &, 172 \\
X2.1 &, 156 &, 083 &, 921 &, 092 &, 235 &, 044 \\
X2.2 &,- 026 &, 127 &, 169 &, 205 &, 043 &, 897 \\
X2.3 &, 940 &,- 018 &, 163 &,- 037 &,- 024 &,- 036 \\
X2.4 &,- 018 &, 080 &, 202 &, 864 &, 124 &, 148 \\
X2.5 &,- 220 &, 788 &,- 018 &, 160 &, 030 &, 042 \\
X3.1 &, 836 &, 042 &, 030 &, 132 &, 183 &, 073 \\
X3.2 &, 207 &, 621 &,- 163 &, 306 &, 243 &, 149 \\
X3.3 &, 339 &, 103 &, 184 &, 277 &, 761 &, 045 \\
X3.4 &, 153 &, 083 &, 884 &, 052 &, 233 &, 061 \\
X3.5 &,- 197 &, 278 &, 222 &, 165 &, 809 &, 106 \\
X4.1 &,- 070 &, 488 &, 236 &, 215 &, 482 &,- 231 \\
X4.2 &,- 193 &, 241 &, 233 &, 170 &, 829 &, 055 \\
X4.3 &, 110 &, 396 &, 572 &, 445 &, 098 &, 206 \\
X4.4 &, 059 &, 252 &,- 013 &, 730 &, 249 &, 085 \\
X4.5 &, 929 &,- 033 &, 148 &,- 028 &,- 059 &,- 072 \\
X5.1 &,- 274 &, 771 &, 164 &, 277 &, 109 &, 051 \\
X5.2 &, 122 &, 843 &, 312 &, 119 &, 212 &, 155 \\
X5.3 &, 931 &,- 065 &, 085 &, 008 &,- 022 &,- 034 \\
X5.4 &, 076 &, 077 &, 906 &, 087 &, 199 &, 045 \\
X5.5 &,- 053 &, 153 &, 063 &, 165 &, 059 &, 912 \\
\hline Ex15acis
\end{tabular}

Extraction Method: Principal Component Analysis.

Rotation Method: Varimax with Kaiser Normalization.

a. Rotation converged in 7 iterations.

Penentuan input variabel ke faktor tertentu mengikuti pada besar korelasi antara variabel dengan faktor, yaitu kepada yang korelasinya besar.

Sebagai langkah terakhir dari penentuan faktor-faktor maka dapat dilihat pada output Component Transformation Matrix. Dimana terlihat pada diagonal-diagonalnya memiliki angka yaitu F1 = 0,152; F2 = -0,288; F3 = -0,783; F4 = -0,164; F5 = -0,315; dan $\mathrm{F} 6=0,661$.

Tabel 4. Component Transformation Matrix

Component Transformation Matrix

\begin{tabular}{|c|c|c|c|c|c|c|}
\hline Component & 1 & 2 & 3 & 4 & 5 & 6 \\
\hline 1 & $\mathbf{1 5 2}$ &, 503 &, 473 &, 492 &, 465 &, 204 \\
2 &, 910 & $\mathbf{- , 2 8 8}$ &, 235 &,- 145 &,- 024 &,- 111 \\
3 &, 353 &, 208 &,- 783 &, 445 &,- 071 &, 128 \\
4 &, 006 &,- 079 &, 247 &, $\mathbf{1 6 4}$ &,- 648 &, 697 \\
5 &, 148 &, 782 &,- 002 &,- 511 &,- 315 &,- 084 \\
6 &, 050 &,- 061 &,- 216 &,- 501 &, 510 &, $\mathbf{6 6 1}$ \\
\hline
\end{tabular}

Extraction Method: Principal Component Analysis.

Rotation Method: Varimax with Kaiser Normalization. 
Dari hasil tersebut maka dapat disimpulkan bahwa ada satu komponen yang memiliki angka lebih besar dari 0,5.

\subsection{Pembahasan}

Dari 5 dimensi yang diteliti dengan 25 variabel, melaui proses uji data dan factoring bisa direduksi menjadi 6 faktor dengan 25 variabel yaitu sebagai berikut:

a. Faktor Pertama (F1):

1) Karyawan selalu menunjukkan kesabaran dan perhatian terhadap konsumen. (X2.3).

2) Karyawan menguasai kualitas, fungsi, cara kerja serta kebutuhan produk yang akan didapatkan konsumen. (X3.1).

3) Karyawan memahami kebutuhan spesifik konsumen. (X4.5).

4) Fasilitas dan sarana parkir tersedia dan luas, pintu masuk dan keluar parkir (lalu lintas) parkir mudah, area parkir tidak jauh dengan pintu masuk toko. (X5.3).

Karena korelasi X2.3, X3.1, X4.5, X5.3 adalah positif sebesar 0,152, maka faktor tersebut berpengaruh dengan kualitas pelayanan terhadap kepuasan Konsumen Toserba Sabar Subur Cikupa Tangerang.

b. Faktor ke dua (F2):

1) Karyawan selalu mengupayakan layanan yang bebas dari kesalahan (X1.5).

2) Kecepatan pemrosesan keluhan konsumen (X2.5).

3) Karyawan memiliki pengetahuan memadai untuk menjawab pertanyaanpertanyaan konsumen (X3.2).

4) Kesigapan karyawan melayani sebelum diminta bantuan oleh konsumen dalam mencari produk yang akan dibeli (X4.1).

5) Tampilan fisik gedung Toserba Sabar Subur Cikupa Rapih, bersih, nyaman, lokasi toko mudah diakses (X5.1).

6) Alat pendukung untuk berbelanja selalu tersedia dalam keadaan tertata rapih dan bersih di pintu masuk toko seperti trolli dan keranjang belanja (X5.2).

Karena korelasi X1.5, X2.5, X3.2, X4.1 X5.1, X5.2 adalah negatif sebesar -0,288, maka faktor tersebut rendah berpengaruh dengan kualitas pelayanan terhadap kepuasan Konsumen Toserba Sabar Subur Cikupa Tangerang.

c. Faktor ke tiga (F3):

1) Karyawan bersungguh-sungguh untuk membantu memecahkan masalah konsumen. (X1.4).

2) Karyawan menghampiri konsumen sebelum konsumen meminta bantuan dan selalu mengucapkan "selamat pagi/siang/sore/malam dan ada yang bisa saya bantu". (X2.1).

3) Karyawan secara konsisten bersikap sopan dalam melayani kebutuhan konsumen. (X3.4). 
4) Sikap baik dan ramah karyawan pada saat melayani dan aktifitas pada saat diarea penjualan. (X4.3).

5) Tersedianya fasilitas pembayaran selain tunai. (X5.4).

Karena korelasi X1.4, X2.1, X3.4, X4.3 X5.4, adalah negatif sebesar -0,783, maka faktor tersebut rendah berpengaruh dengan kualitas pelayanan terhadap kepuasan Konsumen Toserba Sabar Subur Cikupa Tangerang.

d. Faktor ke tiga (F4):

1) Karyawan cepat dalam menyediakan permintaan konsumen sesuai waktu yang dijanjikan. (X1.2).

2) Karyawan tepat dalam memberikan layanan sesuai dengan kebutuhan konsumen. (X1.3).

3) Karyawan selalu dapat menyelesaikan keluhan konsumen. (X2.4).

4) Karyawan selalu mengutamakan kepentingan konsumen. (X4.4).

Karena korelasi X1.2, X1.3, X2.4, X4.4 adalah positif sebesar 0,164, maka faktor tersebut berpengaruh dengan kualitas pelayanan terhadap kepuasan Konsumen Toserba Sabar Subur Cikupa Tangerang.

e. Faktor ke tiga (F5):

1) Karyawan menguasai layout/tata letak produk diarea jual semua bagian dengan baik. (X1.1).

2) Karyawan selalu memberikan rasa aman kepada konsumen dalam berinteraksi. (X3.3).

3) Penyelesaian setiap keluhanan cepat dan memuaskan, memberikan penjelasan dari setiap keluhan yang didapatkan konsumen serta memberikan solusi dari keluhan tersebut. (X3.5).

4) Kesigapan, kerapihan, kecepatan dan ketelitian personel kasir pada saat melayani transaksi pembayaran serta dapat mengurai antrian konsumen di kassa dengan baik. (X4.2).

Karena korelasi X1.1, X3.3, X3.5, X4.2 adalah negatif sebesar -0,315, maka faktor tersebut rendah berpengaruh dengan kualitas pelayanan terhadap kepuasan Konsumen Toserba Sabar Subur Cikupa Tangerang.

f. Faktor ke tiga (F6):

1) Karyawan memberikan kepedulian yang lebih dalam memberikan pelayanan terhadap konsumen misalnya seperti "membantu membawakan barang belanja menuju kassa atau mengantarkan barang belanjaan setelah transaksi dikassa menuju kendaraan". (X2.2).

2) Tersedia ruang tunggu yang nyaman. (X5.5).

Karena korelasi F2.2, X5.5 adalah positif sebesar 0,661, maka faktor tersebut sangat berpengaruh dengan kualitas pelayanan terhadap kepuasan Konsumen Toserba Sabar Subur Cikupa Tangerang 


\section{KESIMPULAN DAN SARAN}

\subsection{Kesimpulan}

Berdasarkan hasil penelitian dan pembahasan yang sudah dijabarkan dalam bab sebeumnya, dapat disimpulkan sebagai berikut :

1. Dari 25 variabel awal setelah melalui proses uji data dan proses analisis faktor, bisa reduksi menjadi 6 faktor yang mempengaruhi kualitas pelayanan terhadap kepuasan konsumen di Toserba Sabar Subur Cikupa Tangerang

2. Berdasarkan besarnya korelasi antara variabel dengan faktor, dua belas variabel yang terbentuk dari proses reduksi dikelompokan menjadi enam faktor.

a. Faktor yang pertama (F6) dengan nilai loading faktor 0,661. Faktor tersebut yang paling dominan mempengaruhi kualitas pelayanan terhadap kepuasan Konsumen Toserba Sabar Subur Cikupa Tangerang, terdiri dari variabel X2.3, X3.1, X4.5, X5.3.

b. Faktor ke dua (F4) dengan nilai loading faktor 0,164. Faktor tersebut mempengaruhi kualitas pelayanan terhadap kepuasan Konsumen Toserba Sabar Subur Cikupa Tangerang,terdiri atas variabel X1.5, X2.5, X3.2, X4.1 X5.1, X5.2.

c. Faktor ke tiga (F1) dengan nilai loading faktor 0,152. Faktor tersebut mempengaruhi kualitas pelayanan terhadap kepuasan Konsumen Toserba Sabar Subur Cikupa Tangerang, terdiri atas variabel X1.4, X2.1, X3.4, X4.3 X5.4.

d. Faktor ke empat (F2) dengan nilai loading faktor -0,288. Faktor tersebut rendah mempengaruhi kualitas pelayanan terhadap kepuasan Konsumen Toserba Sabar Subur Cikupa Tangerang, terdiri atas variabel X1.2, X1.3, X2.4, X4.4.

e. Faktor ke lima (F5) dengan nilai loading faktor -0,315. Faktor tersebut rendah mempengaruhi kualitas pelayanan terhadap kepuasan Konsumen Toserba Sabar Subur Cikupa Tangerang, terdiri atas variabel X1.1, X3.3, X3.5, X4.2.

f. Faktor ke enam (F3) dengan nilai loading faktor -0,783. Faktor tersebut rendah mempengaruhi kualitas pelayanan terhadap kepuasan Konsumen Toserba Sabar Subur Cikupa Tangerang, terdiri atas variabel F2.2, X5.5.

\subsection{Saran}

Dengan hasil penelitian ini diharapkan mampu memberikan sumbangsih dalam dunia peritelan indonesia untuk selalu meningkatkan pelayanan kepada masyarakat sehingga masyarakat akan terpuaskan dengan pelayanan yang diberikan khususnya pada Toserba Sabar Subur dan Toserba maupun mall pada umumnya. 


\section{DAFTAR PUSTAKA}

Gunawan, Imam. 2016. Pengantar Statistik Inferensial. Jakarta : PT. Raja Grafindo Persada.

Kotler P. dan Keller Kevin Lane, 2018. Manajemen Pemasaran. Edisi Ketiga Belas, Jilid 1. Jakarta : Erlangga.

Sunyoto, Danang. 2014. Konsep Dasar Riset dan Perilaku Konsumen. Cet.1. Yogyakarta : Center for Academic Publishing Service.

Ghozali, Imam. 2018. Aplikasi Analisis Multivariate Dengan Program IBM SPSS 25. Edisi 9. Semarang : Universitas Diponegoro.

Sugiyono. 2016. Metode Penelitian Pendidikan :Pendekatan Kuantitatif, Kualitatif dan RnD. Bandung : Alfabeta.

Sugiyono. 2017. Statistika Untuk Penelitian. Bandung : Alfabeta.

Supranto, J. 2010. Analisis Multivariat Arti dan Interpretasi. Jakarta : Rineka Cipta

Widarjono, Agus. 2015. Analisis Multivariat Terapan. Yogyakarta : UPP STIM YKPN.

Sudarno, etal. 2011. "Analisis Kualitas Pelayanan dan Pengendalian Kualitas Jasa Berdasarkan Persepsi Pengunjung”. Jurnal Media Statistik, Vol 4, No. 1, Mei 2015:33-34. 